2 A.M. on Oct. 18th, when he awoke with pain in his abdomen, vomited several times, and passed a loose motion. Dr. Whecler saw him in the evening of that day and found his temperature $101^{\circ} \mathrm{F}$. and the boy complained of mach pain and tenderness in the croal region. All next day (Oct. 19th) he continued in pain and suffered from nausea; his temperature rose to $103^{\circ}$. On the afternoon of Oct. 20 th it rose to $104^{\circ}$ and as the boy was obvionsly worse he was sent to the hospital. On admission he was found to be a thin pale lad, evidently very ill, with a pained, anxious expression; the temperature was $103 \cdot 6^{\circ}$, the pulse was 130 , and the respirations were 36 . The abdomen was rigid and did not move in respiration; its lower part was somewhat distended. The whole abdomen was tender, but the tenderness was very acute in the right iliac region; the boy also pointed to the right loin as a very painful part. The rectum was full of frecs and nothing could be felt through it. I could not make out any distinct lump in the cæcal region. $I$ regarded the case as one of acute inflammation of the appendix with perforation and infection of the general peritoneal cavity, and determined to operate at once. "When the anæsthetic was given the abdomen became much flitter and softer and then a very slight swelling or sense of falness could be made out over the cæcum. I made an incision two inches in length through the skin and superficial fascix and split the three abdominal muscles and divided the transversalis fascia. The subserous fascia was very cedematous and on picking through it a kead of pus appeared at the outer part of the wound. On following this up I opened a small abscess which held about two drachms of thick indol-smelling pus and lay entirely outside the peritoneum and behind the cæoum. This was washed clean and then the peritoneum was divided. The appendix was exposed, lying to the outer side of the cæcum; it had a very short mesentery and was entirely intra-peritoneal ; its distal half was intensely inflamed, its proximal half was dilated and filled with offensive pus, and the mucous membrane lining it was gangrenous. There were three perforations of the appendix. I ligatured the appendix close to the crecum and cut it off close to my thread. There was no lymph or pus in the peritoneal cavity and the cæcum was not injected. There were no adbesions around the appendix which lay quite free in the general peritoneal cavity. Two tubes were placed in the wound-one in the peritoneum and the other in the abscess cavity. The boy made a very good recovery. On Oct. 25 th the peritoneal tube was removed, and the other one the next day. Alihough the sloughing of the appendix appeared to extend quite up to the cæcum no fæcal fistula formed and the lad left the hospital with the wound soundly healed in November.

I have included this case in my list because, as in most of the others, an acutely inflamed, gangrenous, and perforated appendix lay free in the general peritoneal cavity not shut off by any limiting adhesiors. Clinically it resembled exactly several of the others, especially Cases 1,2 , and 5 . Pathologically, however, it stands alone, for around this perforated and sloughing appendix there was no inflammatory effusion, but a clean dry peritoneum; while, on the other hand, there was a small extra-peritoneal abscess. In this fact lies the chief interest of the case. All now recognise the intra-peritoneal origin of perityphlitic abscesses. Thus Treves ${ }^{1}$ writes: "Abscesses resulting from mischief in the cæcum or appendix are primarily intra-peritoneal and are encysted forms of suppurative peritonitis. Inasmuch as the cæcum and vermiform process are normally entirely surrounded by serous membrane any inflammation extending from them must first implicate the peritoneum." Dr. H. P. Hawkins in his "Diseases of the Vermiform Process" adopts the same view, but admits that it is "possible for an extra-peritoneal suppuration to arrive from disease of the appendix" either from extension of the necrosing process through the peritoneum which covers the iliacus muscle or "when the appendix is adberent to the liacus peritoneum a perforation of it on the adherent side may lead directly to inoculation of the retro-peritoneal tissue, so that a large abscess may form in the iliac fossa with little or no affection of the peritoneum." My case is peculiar because the extra-peritoneal abscess was not formed in either of these ways ; the appendix was not adherent anywhere, nor was the iliacus peritoneum inflamed, much less perforated. The condition of the parts at the operation was so plainly seen and so distinct that I think I am entitled to

I The Surgical Treatment of Perityphlitis, second edition, p. 22. say that in this case there was no error of observation sucb as explains the older records of extra-peritoneal perityphlitic abscess. The explanation of the fact I think is this, the lymphatics must bave carried away all the infective material so rapidly and completely that no development of bacilli coli could take place within the peritoneal cavity, but in the lympiatic plexuses ontside the peritoneam the bacilli accumalated multiplied and excited suppuration. In other words the scavenging of the peritoneum was too perfectly $\in$ ffected for inflammation to occur. In support of this view is the fact that in spite of the presence of an appendix with three perforations in it no escaped matter and no exudation of any kind was found around it. A somewhat analogous condition is quite commonly met with in secondary infective abscesses in other parts when a more or less extensive area of bealthy tissne intervenes between the point of inoculation and the secondary abscess in the cellular tissue.

The cases, I hope, tell their own story and I need add but little to the brief comments on each. Pronounced romiting was a very marked symptom in two of the fatal cases (Cases 7 and 8) and was not a troublesome symptom in any of those that recovered. I regard frequent vomiting as a very grave symptom; it is generally reccgnised as a sign of affection of a wide area of the peritoneum.

The mode of cleansing the peritoneal cavity should be varied with the conditions found at the operation. If the effusion is limited to the immediate neighbourhood of the appendix careful and gentle wiping with a sponge is the best means to employ, but where a more general effusion is found a thorough flushing out of the cavity with a sterilised anc? non-irritating fluid is the best method. I prefer a drainagetube to a gauze tampon. Glass tubes are certainly not indispensable and are only superior to rabber tubes in those cases in which the pelvis has to be drained. Rubber tubes should certainly be used for draining the iliac fossa. I prefer a single large rubber tube to two of smaller calibre.

Queen Anne-street, W.

\section{CONSUMPTION, A "FILTH DISEASE."}

By ARTHUR RANSOME, M.D. CANTAB, F.R.S., CONSULTING PHY8ICIAN TO THE MANCHEgTR HOSPITAL FOR CON* SUMPTION AND DISEASHS OF THE THROAT.

SIR JOHN SIMON, in his admirable account of the class off complaints which be brands as "filth diseases," attributes them mainly to two "gigantic evils" in the sanitary government of England: "First, the omission (whether through neglect or through want of skill) to make due removal of refuse matters, solid and liquid, from inbabited places"; and, "second, the licence which is permitted to cases of dangerous infectious disease to scatter abroad the seeds of their infection." He calls attention especially to the class of "diarrhoeal" diseases, such as diarrhœa and dysentery, cholera, and enteric fever, and he regards the last-named as "the very type and quintessence" of all the diseases which are attributable to filth. He says : "Though sometimes by covert processes which I will afterwards explain, yet far of tener in the most glaring way, it apparently bas an invariable source in that which of filth is the filtbiest; that apparently its infection runs its course, as with successive inoculations from man to man, by the instrumentality of the molecules of excrement which man's filthiness lets mingle in his air and food and drink." "There are houses, there are groups of houses, there are whole villages, there are considerable sections of towns, there are even entire and not small towns, where general slovenliness in everything which relates to the removal of refuse matter, slovenliness which in very many cases amounts to utter bestiality of neglect, is the local babit" (p. 463).

Phthisis is not included in the list of "filth diseases" and the omission was certainly intentional ; for whilst Sir John Simon admits that foulness of air due to non-removal of the volatile refuse of the human body is strictly within the physiologist's definition of filth, yet for the purpose of the report the question of overcrowding is set aside as distinct and the word "filth" is used only in that sense which

I A paper rear at a meeting of the Bournemouth Medical Society

I A paper read at a meeting of the Bournemouth
on Nor. 10th, 1897.
${ }_{2}$ Public Health Reports, vol. ii., p. 759 
suggests subject matter for sewers and scavenging. Notwithstanding this arbitrary definition, however, it may be contended that, in spite of all reservations, phthisis comes rightly within the class of filth diseases and the eminent writer of the report would probably be one of the first to acknowledge this. What, in fact, can be conceived as more fitted to come within the desiyration of filth than the loathsome $\epsilon$ xcretions from the lungs of phthisical patients? And what can better illustrate "utter bestiality of neglect" than the habit of voiding these excretions on the floors or on the ground of any place in which these patients may find themselves? The material of this expectoration contains, as is well known, myriads of the "seeds of infection." If this falls upon congenial soil it retains its vitality for long periods of time, even increasing in virulence if it is allowed to remaim in this environment long enough for fresh colonies of the microbe to form. It may also dry up, may become powdered into tuberculous dust, and may then be wafted into the air to be breathed into the Inngs of susceptibl. persons or to be deposited in milk or in other foods and may thus pass into the bodies of children or delicate persons predisposed to the reception of the disease. In one or another of these ways it comes strictly within the description given of a filth disease and in its effects it is infinitely more deadly than enteric fever, the "type and cuintessence" of these disorders.

There are, in fact, many points of resemblance between tuberculous disease and enteric fever. The specific organism in each is a bacillus, remarkably long-lived in suitable surroundings, bat easily deprived of its virulence by the action of sunlight. They are both "facultative saprophytes"-that is, though they are ordinarily parasites they can exist and even grow outside the body in the presence sometimes of very small portions of organic matter. Neither disease is directly infections. They both spread by means of the excretions from the body: phthisis chiefly by the intervention of "tuberculous dust" conveyed into the longs by the medium of the air, enteric fever chiefly in drinking-water, by which means it passes into the intestines. $B$ th diseases may, however, be conveyed either by air or by articles of food or drink.

It is not necessary to lay stress upon the similarity between the lesions produced by these diseases, but it may be incidentally pointed out that Villemin showed that tuberculosis shares with syphilis, glanders, and enteric fever the character of forming "caseous" material. In his Gulstonian Lectures on Tubercle also Dr. Southey showed that typhoid lymphomata are very like tubercle both in their composition and their course affecting similar parts and leading to like lesions. He places tubercle between cancer and these other lymphomata. It is significant of the likeness between phthisis and enteric fever in respect of their derivation from filth that in this country both complaints have greatly declined in frequency since the general improvement of drainage and water-supply. In the last sixty years phthisis has been reduced to one-third of its former prevalence and enteric fever to one-fourth or less.

It is of so mach importance that the connexion between phthisis and filth should be clearly recognised that it will be well to advert briefly to the other evidence which is forthcoming to prove the fact. This evidence is of two kinds-( $A)$ statistical and $(B)$ experimental.

(A) The statistical evidence. -1 . The retarns of the Registrar-General prove that phthisis has declined from over 3800 per $1,000,000$ in 1838 to 1380 in 1894. This is a reduction of about 2500 per 1,000 000 annually or a saving of an army of 75,000 lives in a year, or nearly three quarters of a million in a decade. This great improvement has probably been brought about mainly by the better bygienic conditions of the people, especially as regards subsoil drainage, better dwellings, cleanliness, food and clothing, \&c.--in other words, by a diminution in the amount of filth of various kinds. 2. This view is supported by an analysis of these returns showing the distribution of the disease in overcrowded, unsanitary areas and its incidence upon certain portions of our large towns, its chosen sites being the crowded, shut-in courts and alleys, the back-to-back houses, and the oneor two-roomed tenements where all kinds of filth, but especially air-sewage, abound. 3. That this incidence of the disease is not due simply to poverty or to the poor constitations of the inbabitants or to bad food or ex. posure to the elements or to climate is amply proved by the army and navy returns from all parts of the world. These returns refer exclusively to men who have been chosen from amongst the general population expressly for their health and strength; and it has been proved by Dr. Welch and others that they are less hereditarily predisposed to the disease than the rest of the community. The rejort of the Army Sanitary Commission shows that in soldiers the excessive mortality from phthisis was mainly rue to the "bad ventilation and the imperfect drainage of the barracks" in which they were compelled to live at all the stationg to which these British troops were sent. Similar conclusions are also to be drawn from the Navy Medical Returns. 4. That the disease is not due, however, to ordinary filth is sufficiently proved by the immunity of the fishermen of St. Kilda or of the St. Lawrence River, who live in vile surroundings, their huts being more like pig-sties than human habitations; and the same fact comes out in the history of many a savage tribe. 5 A specific form of impurity is needed; and that this im purity is the peculiarly nasty product of phthisical expectoration is clearly shown by the statistics relating to the German nursing orders collected and published by Dr. Cornet. No one studying these statistics can fail to come to the conclusion that infection from the sick to the healthy had taken place through the medium of taberculous dust produced by the drying up and grinding into powder of the excretions of tuberculous people. The special incidence of the disease upon the novices employed to sweep the floors would almost suffice by itself to point to its source of origin. 6. Bat there are indications in these and other statistics that the specific germ needs a special food and environment either to preserve its existence or to enhance its virulence. The dirty, illlighted, ill-ventilated convent cells were evidently peculiarly favourable to the tubercle bacillus, and a similar conclusion must be formed from the report of the Army Sanitary Commission and from the many other returns from public institutions, prisons, reformatories, \&3., which are given by Parkes in his work on Hygiene, by Hirsch in his "Medical Geography," and by others. 7. Lastly, statistics compiled by Bowditch and Buchanan, by the Registrar-General for Scotland, by Haviland and others show the influence upon the virulence of the disease germ of emanations from a badly drained, impervious subsoil. These observations show at least the probability that certain special forms of impurity have an influence in promoting the infectiveness of the specific germ.

(B) The experimental evidence.-Experimental researches have added weight to the conclusions to be drawn from statistics. (a) We have the observations of Villemin, Schottelius, and others to show that tuberculous material inhaled with the breath or ingested in food or in milk will convey the disease to animals and that it can also be inocalated under the skin. These researches show at any rate that this form of filth can produce the disease. (b) Professor Koch also, as the result of his exbaustive inquiries, came to the conclusion that tuberculous sputum dried up and ground into dust is the most common and most potent of all forms of infective material, and on a review of all the facts it is difficult to frame any other opinion. Cornet, indeed, by researches subsequent to those already mentioned may be said to have proved this point by inoculating guinea-pigs with the dust from rooms, \&c., and thus producing tubercalosis. (c) Experimental evidence is likewise forthcoming to indicate the nature of the special organic impurity which keeps alive the bacillus of tabercle. By means of some researches carried out in the years 1889 and 1890 with the assistance of Professor Dreschfeld, of Owens College, Manchester, I was able to show that the air of a poor cottage in Ancoats, with poor ventilation and undrained basement, in which several cases of phthisis had occurred, was able to preserve unchanged the virulence of tuberculous sputam for two or three months at least, but that the same sputum exposed freely to air and light in a hospital for phthisical patients and also in a well-lighted, well-drained, and wellventilated house entirely lost the power of communicating the disease to guinea-pigs by inoculation. A further research carried on in 1894 in conjunction with Professor Delépine proved that less than two days' exposure to air and light with only one hour of sunshine was sufficient to destroy the virulent power of tuberculous eputum when it was exposed in a clean, well-drained, well-lighted house. Evirently in the air of the Ancoats cottage there must have been some form of organic impurity favourable to the life of the bacillus. 
(d) During the present year (1897) I have been able to demonstrate the character of some of the substances thus capable of promoting the vitality of these " seeds of infection." A vast number of substances have been tried as cultivation media of the bacillus and Beck and Proskauer have shown that in the presence of glycerine most nitrogenous bodies are capable of sustaining its growth at the body temperature. No attempt, however, seems to have been made to test in this respect the influence of the substances most likely to be met with by the organism in its usual habitats and at ordinary temperatures. From a review of the statistical evidence it seemed most probable that some form of impurity commonly present in the air of unsanitary dwellings would be likely to prove a favourable medium of cultivation. A series of experiments was therefore undertaken with the object of testing this point. ${ }^{3}$ The materials chosen for trial were: The condensed vapour from (1) healthy breath; (2) phthisical breath; (3) cellar air (Southampton); (4) cellar air (Bournemouth); (5) a weaver's shed (Blackburn); and (6) pure ground air. These fluids were all carefully sterilised and various substances were used as the supporting medium upon which to sow the seed, such as simple glycerine agar, potato, pure filter-paper, lining wall-paper. All these substances were also sterilised and kept soaked in the fluids mentioned. All the flaids proved to be excellent cultivating media with or without the addition of a small percentage of glycerine. (e) These experiments were carried on at temperatures of from $35^{\circ}$ to $37^{\circ} \mathrm{C}$, but they were all repeated at a temperature of about $20^{\circ} \mathrm{C}$. in order to learn whether the usual conditions of many cottage homes would suffice to keep the bacillus alive in these media. In a large proportion of instances these latter experiments were also fairly successful and it was thus proved that the virus of tubercle could be kept alive and could even grow under these conditions. There is now certainly nothing extraordinary in these results. Professor Koch indeed asserted, on the basis of his own experiments, that the bacillus of tubercle is a true parasite and that it could only be cultivated at, or near, the temperature of the human body; that it could not therefore have a saprophytic existence or live and grow at the ordinary temperatures of cottage dwellings. Other observers, however, notably Sir Hugh Beevor, Dr. Kanthack, and Professor Delépine, have succeeded in cultivating the microbe on potato at comparatively low temperatures, and, as mentioned above, I have myself been successful with the media which I have employed. It may then be now regarded as certain that the bacillus can grow outside the body whenever it can get hold of a sufficiently impure soil and whenever its activity is not interfered with by the adverse conditions of abundant air and daylight. The filth-origin of the germ of phthisis and the sustaining influence of external filth upon its further growth may therefore be taken as proved.

The conclusion that phthisis is a filth disease is not likely to pass without protest from those cleanly people whose families have suffered from the complaint. They will feel it to be a slur upon their reputation and will ask wherefore it should come nigh their wholesome dwellings? The truth is that both enteric fever and phthisis have the power of operating at a distance. Sir John Simon says with reference to the former: "Filth does not only infect where it stands, but can transmit its infective power afar by certain appropriate channels of conveyance. ...... Thus it has again and again happened that an individual house, with every apparent cleanliness and luxury, has received the contagium of enteric fever through some unguarded drain inlet, or that numbers of such houses have simultaneously received the infection as an epidemic in places where the drain inlets in general have been subiect to undue air-pressure from within the sewer. It has again and again happened that households while themselves without sanitary reproach have received the contaginm of enteric fever through some nastiness affecting (perbaps at a considerable distance) the common water-supply of the district in which they are" (p. 465). He instances the case of Windsor when the highest persons in the land were affected and the cases of Croydon and Worthing. Much the same may be said of phthisis, from which complaint many have suffered whose houses are above reproach, though it may be doubted whether there are not many even of the luxurious homes of the rich where air sewage is not merely allowed to remain, but where it is

3 This research was communicated to the Royal Society on Nov, 25th, 1897 (see Proceedings of the Royal Society). even closely stored up by the precautions taken against cold and dranght. Even where there is an abundance of fresh air and sunlight is it certain that the inmates of these perfectly hygienic houses never visit places where the specific forms of filth are to be found in abundance and in full possession of all their virulence? What are we to say of many of the places frequented by these otherwise happily situated individuals? What of the constantly attended' places of public resort? What of the theatres, concerthalls, assembly rooms, churches, chapels, \&c.?

Theatres as at present constructed are often mere deathtraps to delicate, susceptible people. These so-called temples of the Thespian art are often charged with many different forms of pathogenic microbes ready to flourish into disease when they meet with congenial soil. They are nightly filled with people some of whom at least are in one or another of the stages of phthisis, and though perhaps many of them are too well bred to expectorate upon the floors others are not so particular and nearly all carry about with them handkerchiefs laden with tuberculous material. The halls and passages and galleries of these places and even their anditoria are seldom if ever visited by the rays of sunlight and their atmospheres are overcharged with carbonic acid and ammoniacal or sulphurous vapours. They are imperfectly ventilated, chiefly in many cases by the spent and disease-laden air from the stage and wings where the employés are still more liable to be in advanced stages of phthisis and where they are still less likely to abstain from spitting upon the floors, scenery, \&c. They are true hotbeds and forcing grounds in which may be kept alive and even cultivated the germs of tuberculous and other diseases.

Concert halls and assembly rooms are in little better case than theatres in respect of their appliances for ventilation, for cleanliness, and for the admission of sunlight.

What again shall we say of churches and chapels and other places of public worship? Is it not notorious how badly they are ventilated and how little their "dim religious light" can do to disinfect the germs of disease? Let anyone gifted with an ordinary sense of smell or who knows what fresh air means enter almost any of these assemblies for public worship, even after only a short service, and let him describe the atmosphere he will meet with on entering. It is charged with "air sewage" of the vilest quality, the imperfectly removed emanations from hundreds or thousands of human bodies. There is probably less visible filth than in places of amusement; but even here there can be no doubt that there is plenty of tuberculous dust floating about in the air and the conditions it finds there are well calculated to keep it alive and to preserve its virulence. Here again therefore we have an important source of danger to the individuals whose case we are now considering. There is also danger in closely shut up and badly ventilated vehicles such as omnibuses and railway carriages; and, in fine, we have not far to look for sources of phthisis in most of the haunts of ordinary so-called civilised life. It cannot be said, therefore, that any direct blame attaches to the families of those who have fallen victims to phthisis. The opprobrium rests rather with the supreme health authorities and with the general public for allowing places of public resort to remain in such a condition as to be a serious source of danger to their frequenters. It is a public scandal that places of amusement and our temples of worship should be allowed to remain without adequate ventilation and without frequent and periodical purification.

It is possible that, owing to the terms in which I have described the dangers arising from places of public assembly, I may be accused of attempting to increase the "scare" of infection which at present undoubtedly possesses the public mind, but this is very far from my intention. I believe that in temperate climates direct infection from patients is one of the rarest events. It is only when tuberculous filth is scattered about in places fitted to keep alive the bacillus that infection becomes probable and it is therefore against the retention of gross impurities in the air that the above remarks have been written. I have elsewhere given my reasons for concluding that in well-kept, cleanly, well-aerated, and well-lighted dwellings ${ }^{4}$ there is little, if any, danger of infection from phthisical persons. On the other hand, I believe strongly in the danger of infected, insanitary houses and even infected areas, and it has been owing to that conviction that I have ventured to raise a protest against the 
filthy habits of communities and against the vile condition of our public assembly rooms under which infection from phthisis is only too likely to take place.

It will be gathered from what has been said that in my opinion it is not the person of the phthisical subject that is to be dreaded but the conditions under which he lives. It is true that, like the typhoid ferer patient, he is the source and origin of the infective material, bat he is not himself directly infectious. In the case of enteric fever it is well known that if proper care is taken to disinfect and to dispose of the excreta there is no risk of infection to the attendants, and the same immunity can be claimed under this condition for the nurses of phthisical persons.

The measures to be adopted in order to prevent the spread of phthisis are indeed very similar to those required for staving off an epidemic of enteric fever with this difference, that instead of paying especial attention to drains and sewers and to the condition of the drinking-water it is the purification of the air, the admission of sunlight, the drainage of the subsoil, the provision of dampproof courses and concrete basements that must be chiefly attended to for the prevention of phthisis. The means which are used and which have been to a great extent successful for the suppression of enteric fever are- $(a)$ notification of disease, $(b)$ disinfection of excreta, $(c)$ hospital treatment, and (d) general sanitary measures. Similar methods, with certain modifications to suit the differences between the conditions of the disorders, must be adopted for the suppression of phthisis. Thus $(a)$ the notification of phthisis can hardly be made compulsory as in the case of enteric fever. Phthisis usually runs a much more chronic course than typhoid fever; it is not unfrequently difficult to make an accurate diagnosis; and the announcement of its presence would be regarded by many as a blot upon the family escutcheon, especially among the upper classes of society. Notification amongst these classes would indeed be almost useless since no medical officer would interfere with the private medical practitioner, and we may be sure that for their own sakes these families would take every care to prevent the spread of infection. In Manchester a plan of procedure was formulated a few years ago at a meeting, called together at my suggestion, of the medical officers of the Hospital for Consumption, some of the physicians of the Royal Infirmary, and Dr. Tatham, then the medical officer of health of Manchester. It was proposed that the medical officer of health should send to the medical men then present, and to any others willing to carry out the modified notification, post-cards addressed to himself, which should be filled up with the names and addresses of phthisical patients in whom the disease had advanced as far as excavation or in whose sputum bacilli had been detected. Only those cases were to be reported which were likely to spread infection owing to the state of their dwellings or to want of means or of will, to disinfect. These cards were to be countersigned by the patients themselves. On his part the medical officer of health promised to send to these people carefully drawn up papers of instructions stating the precautions to be taken with the sputum or other excreta and directions as to ventilation and admission of sunlight. He also offered to disinfect free of charge any dwelling likely to be a source of danger. This plan of campaign was adopted both in Manchester and in Salford and was to some extent carried out not only in these towns bat in the surrounding district. It was also unanimously approved of by the north-western branch of the Association of Medical Officers of Health. ${ }^{5}$ (b) Destruction of the bacillus in the excreta must be carried out by 1 per 500 solutions of corrosive sublimate, by fire, or by sluicing away the already disinfected excreta into the sewers. Infected houses must be treated by brushing over all surfaces with 1 per cent. solutions of chloride of lime according to Professor Delépine's directions. (c) Although in so chronic an ailment hospital accommodation cannot be provided for all the cases likely to require isolation yet it would undoubtedly be a great benefit both to the sufferers themselves and to the general community if all who were without proper lodging and accommodation or who were unable themselves to take proper precautions could be received for treatment into fitting homes. May we not hope that in the near future local authorities will see the importance of establishing

5 A somewhat similar scheme has also for the last year or two been arried out in New York. (See report of the medical officer of health.) in connexion with fever hnspitals wards for the reception of all such cases? It is much to be regretted that the funds formerly so lavishly provided for the segregation of lepers are not now available for the treatment of the strictly analogous disease, tuberculosis. (d) The last of the measures to be directed against the spread of these "filth diseases"-namely, sanitary reform-is also probably the most important. We know how efficient it has been against enteric fever, and it is probable that when it is once fairly directed against tuberculosis it will be equally successful. Already the simple measures of improved drainage, better house accommodation, better food, \&c., which have diminished the death-rate from enteric fever, have had some effect upon the mortality from phthisis, reducing it by nearly two-thirds, as I have already pointed out. Some more special means will, however, have to be adopted if the remaining third of this mortality is to be abolished. Particular attention will have to be paid, as we have seen, to the condition of the air in all places of public assembly and a much higher standard of ventilation will have to be ensured in all workshops, weaving sheds, and in all rooms occupied by working people. It is much to be desired that the standard recently proposed by the Home Office Committee on Cotton Cloth Factories, of which I was a member, could be applied to all places where manual labour is carried on. Again, " air-sewage" must ke promptly carried away or destroyed in all the densely populated recesses of our towns and in order that the natural enemies of the tubercle-bacillus-fresh air and sunlight-may have free scope to act local authorities will everywhere be obljged to carry out extensive works of re-construction and will have to put in force the strongest powers they now possess for preventing the pollution of the atmosphere by smoke or noxious vapours; they must open out all confined areas, must destroy all insanitary house property, and must provide ample lung space in the shape of public parks and playgrounds. It would be well also if all towns would follow the enlightened policy of Liverpool and London and obtain powers for securing that an adequate space shall be left around all houses or buildings in the future and that ground air shall be excluded from buildings by efficient concrete basements, damp-proof courses, \&c. Owing to the recognition of the fact that enteric fever can be stamped out by attention to the water-supply and by the proper disposal of abdominal excreta this disease has now come to be regarded as entirely preventable and its presence is felt to be an opprobrium upon the sanitary management of the community. If it could be made plain to men's minds that phthisis is likewise essentially a "filth disease," and if the means of disposing of the "air sewage" from which it springs could be clearly shown to the people, its presence as an endemic in any community would quickly come to be equally regarded as an opprobrium and the disease would soon be as great a rai ty as leprosy.

Bournemouth.

\section{CASES OF URETERECTOMY AND NEPHRO. URETERECTOMY-PARTIAL AND} COMPLETE.

BX HENRY MORRIS, M.A., F.R.C.S. ENG., SURGEON TO THE MIDDLESHX MOSPITAL.

WHEN performing nephrectomy if the ureter is found to be dilated and suppurating, as it often is in calculous and some other affections, or is in a condition of tuberculong ureteritis it ought to be removed in part or to the whole of its extent. Ureterectomy partial and complete: is, in fact, an important adjunct to nephrectomy and may be performed either at the same time or subsequently according to circumstances. If done as a primary operation it prevents the formation of a fistula which otherwise would follow nephrectomy for some forms of pyonephrosis or tuberculous disorganisation of the kidney. As a secondary operation it is required when a discharging fistula persists due to ureteral disease and not to a suppurating "foyer" in the retro-peritoneal cellular tissue. By ureterectomy is thus meant not the 